\section{Encontros e diálogos entre a saúde e a educação no Brasil}

Helifrancis Condé Groppo Ruela (0000-0002-4862-9460)

Fundação Oswaldo Cruz, Escola Politécnica de Saúde

Joaquim Venâncio, Rio de Janeiro, RJ, Brasil.

$<$ helifrancisconde@gmail.com>

Bertucci, Liane Maria; Mota, André; Schraiber, Lilia B.(Orgs.). Saúde e educação: um encontro plural. Rio de Janeiro: Editora Fiocruz, 2017, 326 p.

Saúde e Educação: um encontro plural é o nome da obra organizada por Liane Maria Bertucci, André Mota e Lilia Blima Shraiber que foi publicada pela Editora Fiocruz em 2017. O livro promove o encontro de historiadores, educadores, médicos e cientistas sociais que se dedicam e dialogam com o processo histórico de construção da relação entre a saúde e a educação, sobretudo no Brasil do século XX, e que têm como referencial condutor a historiografia brasileira. Os 14 capítulos estão agrupados em três partes temáticas que trataremos na sequência, quais sejam: Formação Profissional; Campanhas e Práticas de Prevenção; e O Universo Escolar.

A primeira parte, composta por quatro capítulos, inicia com "Saúde e Educação: a formação profissional entre princípios do século XX e do $\mathrm{XXI}^{\prime \prime}$. Neste capítulo a autora analisa as influências do Relatório Flexner na formação médica na América Latina e como a maioria das instituições incorporou as recomendações sugeridas pelo documento, a saber: privilégio da biomedicina, incorporação de tecnologias, ensino por disciplinas e divisão dos currículos por ciclos. Aponta também que houve uma importante mudança depois da segunda metade do século $\mathrm{XX}$, quando organismos como a OPAS e a OMS passaram a sugerir uma revisão nos currículos dos cursos da área da saúde, visando uma formação que superasse a proposta de ciclos (básico, pré-clínico e clínico) e promovesse uma integração e harmonização entre os conteúdos e a inserção mais precoce dos estudantes nos serviços de saúde locais.

O texto seguinte, intitulado "Educação, Higiene e Profissão em Debate nos Congressos de Medicina Latino-Americanos e Brasileiros", resgata a realização dos Congressos científicos de medicina no continente latino-americano na virada do século XX para o XXI e suas participações na consolidação profissional do médico no período. Com base nos documentos desses eventos foi possível demonstrar a tensão no processo de regulamentação e construção do campo de atuação enquanto áreas autônomas não só da profissão médica, mas também de outras áreas profissionais como a farmácia, a odontologia e a enfermagem.

Já o terceiro capítulo, “Diplomadas de 1946: o novo modelo de formação norte-americano e a Escola de enfermagem do Centro Médico da Faculdade de Medicina de São Paulo", tem como objetivo contribuir para a análise histórica do movimento político e social que alterou a formação e a identidade profissional no Brasil pós-1930. Para isto foram tomados depoimentos das 16 egressas da primeira turma da Escola de Enfermagem de São Paulo.

No último capítulo dessa primeira parte, intitulado "A Cooperação Opas-Brasil na Formação de Trabalhadores para a Saúde (1973-1983): instituições, agendas e atores" são resgatadas as bases, o desenvolvimento, os desdobramentos e resultados da cooperação técnica Opas-Brasil e sua influência no cenário dos recursos humanos em saúde no Brasil. Destaca-se o Programa de Preparação Estratégica de Pessoal de Saúde (PPREPS) e o apontamento de que o legado da cooperação não se restringiu ao tema da formação de recursos humanos para a saúde e acabou influenciando e contribuindo para o próprio movimento de articulação que culminaria na formulação do Sistema Único de Saúde anos mais tarde.

A segunda parte, de uma maneira geral, trata do modo como determinadas populações enfrentaram doenças específicas e o quadro de saúde no final do século XIX e nas primeiras sete décadas do século XX. É iniciada com o capítulo "Morte aos Ratos!" que contextualiza o surgimento da epidemia de peste bubônica na Europa e sua chegada e disseminação no Brasil. São descritas também as estratégias de combate aos surtos e epidemias e suas relações com os ideais civilizatórios e de nação moderna da conjuntura do período.

O capítulo 6 da coletânea que tem como título "Os materiais educativos para a Prevenção do Câncer no Brasil: da perspectiva histórica à dimensão discursiva" discute os aspectos da educação em saúde para o controle do câncer no século $\mathrm{XX}$, sobretudo através da publicação de impressos sobre o tema, elaborados entre as 
décadas de 1940 e 1960. Seus autores mostram como a mudança no padrão de morbidade fruto da transição epidemiológica impactou nas estratégias e práticas de combate ao câncer e como ele ganhou espaço na agenda da saúde pública brasileira depois da década de 1950.

"Saúde e educação na reforma dos Costumes dos Jovens Rurais mineiros (1952-1972): a experiência dos Clubes 4-S" é o terceiro capítulo dessa segunda parte. Os autores discutem a organização dos clubes de jovens rurais e sua ação de extensão rural em Minas Gerais, desenvolvida por funcionários da Associação de Crédito e Assistência Rural (Acar-MG). O projeto buscou uma "reforma dos costumes que tinha a sua centralidade na prescrição de preceitos morais e de saúde para uma parcela significativa da população rural de Minas Gerais, levadas à cabo por iniciativas de educação social"' (p. 185).

O texto que fecha essa segunda parte é "Saúde pública, Mudança de Comportamento e Criação: da educação sanitária à emergência da inteligência coletiva em saúde" que realiza uma breve recuperação histórica da educação em saúde nas práticas de saúde pública no Brasil ao longo do século XX passando pela educação sanitária, a educação popular e a inteligência coletiva. São abordadas suas diferentes formas de interface com a comunicação, com os comportamentos e estilos de vida e como esses foram respondendo às mudanças do perfil epidemiológico de cada período.

A terceira e última parte do livro está estruturada em seis capítulos que tratam do tema da saúde no universo escolar. O texto "Saúde e Educação no Contexto Escolar" é o primeiro deles e busca demonstrar o desenvolvimento do movimento higienista e sua relação com a escola entre a segunda metade do século XIX e as primeiras décadas do século XX. Ele aponta como a higiene passou a condicionar os aspectos da infância, da adolescência, da organização escolar e consequentemente promover uma medicalização da escola. Segundo a autora, “a atual educação para a saúde no universo escolar herdou muitos aspectos da antiga higiene das escolas e dos escolares" (p. 224).

O capítulo seguinte, "Para a Sanidade do Corpo: ginástica e educação física nas actas e pareceres do congresso de Instrucção Publica - Rio de Janeiro, 1883", analisa o material reunido para o congresso que, por falta de recursos, acabou não acontecendo. As Actas e Pareceres acabaram sendo publicados em 1884 pela Typographia Nacional. São feitas considerações sobre a higiene individual e da escola e a importância da ginástica para meninos e meninas como meio de moldar corpos saudáveis.

O terceiro capítulo dessa última parte é "Em Prol do Ofício, da Salvação Pública e de uma Comunidade Produtiva: higiene e saúde na formação de professoras primárias", que se baseia no estudo de dois compêndios de higiene destinados à formação de professoras na escola normal da capital da República. O primeiro foi Noções de Hygiene, de Afrânio Peixoto e Graça Couto, e o segundo Compendio de Hygiene, de José Paranhos Fontenele. As publicações analisadas buscavam preparar as futuras professoras primárias com relação à higiene e aos conhecimentos elementares relacionados à saúde.

O capítulo seguinte "A Saúde pela Educação na Escola (Nova) Primária: artigos de José Pereira de Macedo na Revista Médica do Paraná, início dos anos 1930" traz considerações sobre os artigos publicados pelo médico professor da Faculdade de Medicina que dissertavam, entre outras coisas, sobre a necessidade de inspeção das instalações escolares como as cantinas e a "importância da instrução dos professores pelos médicos e a relevância da atuação desses professores bem formados para inculcar nos alunos noções sobre saúde e prevenção de doenças" (p. 282).

O penúltimo capítulo da coletânea é "Educação Rural, Eugenia e o Caso da Galinha Preta" que apresenta a experiência da Escola Rural do Butantã, mais especificamente da atuação da professora normalista Noêmia Saraiva de Mattos Cruz e suas estratégias de ensino que estimulavam os alunos a refletirem sobre o mundo do trabalho rural, patriotismo e higiene eugênica.

O livro termina com o capítulo "Formação de Cidadãos Higienizados para a Construção do Progresso Nacional: produção e circulação de livros escolares de higiene na primeira metade do século $\mathrm{XX}^{\prime \prime}$, que segue a linha da última parte e trata da relação da higiene com o universo escolar. Nesse caso específico são abordados os livros escolares utilizados para disseminação de saberes e práticas higiênicas nas escolas primárias e nos cursos de formação de professores no referido período.

O percurso da obra que foi aqui traçado mostra o processo histórico de construção da relação entre saúde e educação sob uma perspectiva de forte base empírica. É digno de nota o rigor das 
pesquisas e a abrangência das experiências em termos geográficos, institucionais e áreas de atuação profissional, que são fruto do referencial teórico metodológico guia do livro.

Esse referencial, se por um lado traz uma riqueza de detalhes sobre as pessoas, os lugares e as datas, por outro pode deixar a desejar na análise conjuntural do período analisado. Ainda que em alguns momentos os autores se preocupem em relacionar a saúde e a educação com o momento político-econômico do país, em outros fica pouco evidente ou velada a relação dialética que esse binômio saúde-educação estabelece com o modo de produção social vigente do período. $O$ referencial da determinação social do processo saúde-doença (Breilh, 2013) nos parece central para a realização dessa tarefa.

Assim, reafirmamos a importância da obra como base empírica da história da relação saúdeeducação, ao mesmo tempo em que convidamos os pesquisadores para que em futuros estudos sobre o tema tenham em vista a não neutralidade e a intrínseca relação com o modo de produção social que esses dois campos de atuação possuem.

\section{Referência}

BREILH, Jaime. La determinación social de la salud como herramienta hacia una nueva salud pública (salud colectiva).Revista Faculdad Nacional de Salud Pública, Antioquia, n. 31, supl. 1, p. 13-27, 2013. Disponível em: < http://www.scielo.org.co/pdf/rfnsp/ v31s1/v31s1a02.pdf $>$ 